\title{
A ELABORAÇÃO DO DESIGN DE INTERFACE DA HOMEPAGE PARA O NOVO WEBSITE DO SISTEMA TELESSAÚDE
}

\author{
THE ELABORATION OF THE HOMEPAGE'S INTERFACE FOR \\ TELESSAUDE SYSTEM'S NEW WEBSITE
}

\author{
Priscila Esmeraldino \\ Israel Braglia, Prof. Dr. \\ Universidade Federal de Santa Catarina \\ e-mail: priscimera@gmail.com \\ Universidade Federal de Santa Catarina \\ e-mail: israelbraglia@gmail.com
}

Interface, homepage, website

O presente artigo destina-se à pesquisa de web design, utilizando uma metodologia para criação da interface para o novo site do Sistema Catarinense de Telessaúde e Telemedicina, motivado pela necessidade de aprimorar o atendimento dos profissionais de saúde e população, os quais dependem de serviços ofertados pela plataforma online para realizar diversas atividades. A metodologia tomada como base para construção da arquitetura é a de Jesse J. Garret (2003). Também foram utilizados os estudos de Jacob Nielsen sobre avaliação de interface para homepages. Os resultados obtidos da pesquisa foram uma nova página inicial para o website do Telessaúde, assim como um template.

\section{Interface, homepage, website}

The following article intends to a web design research, using a methodology for the creation of Santa Catarina's Telessaude and Telmedicina system's homepage for their new website - and a base template for the other pages. Motivated by the urgent necessity in upgrade the attendance for the health professionals and population, who depend on services offered by the online platform to realize various activities. Jesse J. Garret's (2003) methodology was taken as base for the building of the information architecture. Jacob Nielsen's studies about interface rating for homepages were also used. The results obtained with the searching were the new homepage for Telessaude's new website and a template.

\section{Introdução}

Com a popularização do oferecimento dos serviços de saúde à distância pelo governo, atualmente existe uma gama de pessoas que os utilizam e dependem deles diariamente para efetuar seus trabalhos (principalmente aqueles que se encontram em municípios muito pequenos e/ou isolados).

Nesse sentido, surge cada vez mais a necessidade de plataformas online que possam atender seus usuários (estes, em geral, profissionais de atenção básica de saúde ou pacientes), de forma a facilitar sua acessibilidade. Tem-se conhecimento de que, muitas vezes, questões de ergonomia e usabilidade não são tidas como eixo principal na construção das mesmas.

Visto a situação em questão, este artigo tem como proposta mostrar, resumidamente, o trabalho concluído para o desenvolvimento de uma nova interface para a homepage do website do Sistema Catarinense de Telessaúde e Telemedicina, utilizando os conhecimentos de avaliação de Nielsen (2001) e a metodologia de Garrett (2011) adaptada.
Realização:

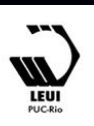


$16^{\circ}$ Ergodesign - Congresso Internacional de Ergonomia e Usabilidade de Interfaces Humano Tecnológica: Produto, Informações Ambientes Construídos e Transporte

$16^{\circ}$ USIHC - Congresso Internacional de Ergonomia e Usabilidade de Interfaces Humano Computador

CINAHPA | 2017 - Congresso Internacional de Ambientes Hipermídia para Aprendizagem.

\subsection{Objetivo geral}

Realizar uma nova proposta de interface gráfica, analisando os resultados da avaliação efetuada, para melhorar o acesso à informação aos usuários do Telessaúde.

\subsection{Justificativa}

O sistema de Telemedicina e Telessaúde (STT) é a unificação dos serviços de Telemedicina e Telessaúde de Santa Catarina, voltados para o SUS.

O serviço de Telemedicina foi criado no Estado, por meio da Universidade Federal de Santa Catarina e a Secretaria de Estado da Saúde (SES/SC) em 2005, para facilitar o acesso dos cidadãos aos exames médicos por meio de acesso online. Possibilitando o envio de exames e emissão de laudos à distância por especialistas da área.

O Ministério da Saúde então criou, em 2007, o programa Telessaúde Brasil. Como Santa Catarina já possuía o Telemedicina e uma cobertura de rede que chegava a pelo menos 60 municípios acabou sendo um dos nove estados escolhidos para ter seu próprio núcleo de Telessaúde. Permitindo assim a estruturação de uma rede de serviços de educação permanente. Em 2009 o Telessaúde consolidou-se também como ferramenta e serviço de educação permanente à distância. ${ }^{1}$

Finalmente, em 2010, a Telemedicina e o Telessaúde foram integrados formando o STT (Sistema Catarinense de Telemedicina e Telessaúde). Neste ano também foi criado o website atual: um único sistema que oferece os serviços específicos da Telemedicina: laudos à distância de diversas modalidades ("Telediagnóstico"), acesso dos pacientes aos seus exames e do Telessaúde: "Webpalestra", "Teleconsultoria" e minicursos à distância (os quais fazem parte do serviço de "Teleeducação"). ${ }^{2}$

O Telessaúde hoje tem como objetivo aprimorar o oferecimento dos serviços aos seus usuários. Tendo isso em vista, percebeu-se a necessidade da elaboração de um novo website para atender às novas demandas. Também, suprir as carências apontadas tanto pelos

${ }^{1}$ Conforme informações no website atual do

Telessaúde 2016.1 - disponível em

$<$ https://telemedicina.saude.sc.gov.br/> Acesso em junho de 2016.

${ }^{2}$ Estas equipes serão melhor mensuradas no capítulo 3 deste documento. usuários externos quanto pelos profissionais que utilizam a plataforma para oferecer-lhes os serviços do Telessaúde ou Telemedicina.

O website atual (2016.1) conta com uma parte externa ao público geral e um acesso restrito, o qual abre uma plataforma online voltada apenas aos usuários cadastrados (em geral profissionais de Atenção Básica de Saúde do estado). Ambas foram elaboradas primordialmente no ano de 2010 e funcionam até o presente, sofrendo apenas alterações pontuais.

Primeiramente foi necessária a construção de toda a área externa. Pois, na área interna poderiam ser alterados apenas alguns elementos da interface, já que o sistema é complexo e sua alteração por completo demandaria muito trabalho. Por isso, no presente trabalho estudouse apenas a interface da página principal (homepage) da área externa do website.

A homepage é o fator crucial para o sucesso de um website e é, sem dúvidas, a página a qual deve receber maior dedicação não só do designer, mas da equipe inteira que participa do projeto. Construindo uma homepage também se obteve uma template - ou seja, um modelo de estrutura base - para se utilizar nas outras páginas do website.

Avaliando a interface gráfica do website antigo foi possível tatear com precisão quais os próximos passos a serem tomados na construção de um novo. Assim como quais erros podiam ser evitados e o que os usuários mais necessitavam naquele momento.

\section{Metodologia projetual}

A metodologia selecionada como guia principal para o desenvolvimento do trabalho foi a proposta por Garrett (2003), descrita em sua obra "The Elements of User Experience" (em tradução livre, "Os Elementos da Experiência do Usuário").

A proposta de Garrett trouxe uma estrutura simples composta por cinco etapas: plano de estratégia, plano de escopo, plano de estrutura, plano de esqueleto e plano de superfície.

É importante frisar de antemão que a metodologia selecionada trabalha com todos os níveis de construção de interface de um website e, no presente trabalho, como já mencionado anteriormente, trabalhou-se apenas na construção da homepage. Sendo assim, utilizou-se uma versão adaptada da metodologia em questão,
Realização:

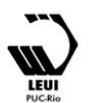




\section{$16^{\circ}$ \\ ERGODESIGN USIHC CINAHPA}

$16^{\circ}$ Ergodesign - Congresso Internacional de Ergonomia e Usabilidade de Interfaces Humano Tecnológica: Produto, Informações Ambientes Construídos e Transporte

$16^{\circ}$ USIHC - Congresso Internacional de Ergonomia e Usabilidade de Interfaces Humano Computador

CINAHPA | 2017 - Congresso Internacional de Ambientes Hipermídia para Aprendizagem. atendendo às limitações do projeto.

Plano de estratégia: É a base de todo projeto. Está focado na especificação do público usuário do website e nos objetivos a serem alcançados com o mesmo. Aqui é necessário entender quais são as necessidades das pessoas em equilíbrio com os recursos estabelecidos.

Plano de escopo: O foco nesta etapa é, utilizando as informações levantadas no plano anterior, definir qual será o conteúdo abordado no website. Segundo Garrett (2003), por um lado é a criação de especificações funcionais (descrição detalhada das características do produto), por outro uma listagem do conteúdo necessário.

Plano de estrutura: Aqui, o design de interação definindo como o sistema comporta-se diante do usuário - e a arquitetura de informação - organizando o conteúdo e definindo a estrutura de navegação do website - são peças chave.

Plano de esqueleto: Nesse ponto, definida a localização dos elementos na interface, organizando-os de modo que os usuários já consigam interagir com a funcionalidade do sistema. $O$ foco é a definição de posicionamento de elementos, não a estética.

Plano de superfície: Como última etapa, a elaboração da interface gráfica, tendo como base sólida o que foi definido nos planos anteriores.

Segundo Garrett (2003), quando a internet começou havia apenas o hipertexto. Nessa situação, o progresso era demorado, já que nem a própria comunidade especializada na experiência do usuário conseguia entrar em consenso. Por isso, Garrett sugere a divisão dos cinco planos ao meio:

À esquerda, põe-se elementos específicos para o uso da Web como a interface de um software. Já à direita, elementos específicos de informações (hipertexto). Aqui a preocupação é a informação. Qual informação o site oferece e o que ela pode significar aos usuários. Segundo Garrett, "hipertexto é sobre a criação de um espaço de informação por onde os usuários podem se mover".

Garrett (2003) explicou que, para o projeto de um website ser efetivo, deve-se ter uma estratégia como fundamento, onde é necessário o equilíbrio entre os objetivos do produto final com as necessidades $\mathrm{e}$ expectativas do usuário. É comum a falha em projetos que começam sem pensar no que se deseja alcançar com o produto final e no que o usuário conseguirá dele.

\subsection{0 retorno do investimento em usabilidade.}

De acordo com Santa Rosa (2012), é comum que as empresas se concentrem unicamente no propósito de gerar receita, ou eliminar gastos, ignorando a análise do objetivo geral do projeto. Por outro lado, há casos em que o foco na funcionalidade é tão específico que se esquece do elemento principal: o usuário final. Segundo Garrett (2003), é necessária certeza de que cada decisão está sendo tomada compreendendo suas consequências, para que se possa criar uma experiência do usuário bemsucedida.

"Incorporar usabilidade no seu processo pode reduzir os custos e tempo de desenvolvimento e melhorar o produto final. Deve-se ter em mente os usuários finais em todas as etapas de desenvolvimento e processos de produção, desde a análise das necessidades e projeto conceitual até prototipagem e produção. " (SANTA ROSA, 2012)

A metodologia de Garrett foi adotada como ideal para este projeto por propor a identificação do público alvo como etapa fundamental. Os usuários do sistema Telessaúde e Telemedicina, mesmo sendo todos, em sua maioria, do meio da saúde, possuem perfis diferentes. Segundo o autor, pesquisas são fundamentais para auxiliar na restrição e priorização de quem são as pessoas que correspondem ao público correto.

\section{Diagnóstico}

Pretendendo-se construir a interface da homepage para o novo website do Telessaúde foi necessário antes estudar o anterior. Para isso, escolheu-se fazer uma avaliação de interface, seguindo diretrizes de usabilidade.

O sistema escolhido como o mais adequado para avaliação de interface de uma homepage foi o definido por Jacob Nielsen em 2001. Segundo este ele, a maior parte das diretrizes de usabilidade definidas no passado ainda são válidas, pois elas resistem porque dependem do comportamento humano, o qual, por sua vez, muda muito lentamente, quando muda.

\subsection{A homepage: sua importância e função.}

Nielsen e Tahir (2001) frisam que a homepage é a página mais importante do website, por ser a mais visualizada dentre as outras páginas. Mesmo que nem
Realização:

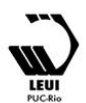




\section{$16^{\circ}$ \\ ERGODESIGN USIHC CINAHPA}

$16^{\circ}$ Ergodesign - Congresso Internacional de Ergonomia e Usabilidade de Interfaces Humano Tecnológica: Produto, Informações Ambientes Construídos e Transporte

$16^{\circ}$ USIHC - Congresso Internacional de Ergonomia e Usabilidade de Interfaces Humano Computador

CINAHPA | 2017 - Congresso Internacional de Ambientes Hipermídia para Aprendizagem. todos os usuários entrem no site diretamente pela homepage, uma de suas primeiras ações é ir a ela para procurar o que necessita.

"A função mais crítica da homepage é transmitir o que a empresa significa, a importância do site em relação à concorrência e ao mundo físico, e os produtos ou serviços oferecidos. " (NIELSEN E TAHIR, 2001)

Cada usuário pode possuir metas e objetivos diferentes dentro de um website. No entanto não é possível enquadrar perfeitamente cada tipo de usuário em uma variedade limitada e opções para cada um. Se a homepage não o ajudar a compreender exatamente por onde ele deve seguir, o mesmo pode ficar frustrado e não retornar ao website outra vez. Os usuários mais experientes, por sua vez, poderão até dar sugestões de como melhorar as carências do sistema.

"O desafio está em estruturar uma homepage que permita acesso a todos os recursos importantes, sem abarrotar a página com todos eles, o que aterroriza, na maioria das vezes, os novos usuários. Acomodação e clareza são fundamentais, assim como perceber os objetivos dos usuários. " (NIELSEN E TAHIR, 2001)

\subsection{As diretrizes propostas por Nielsen.}

A maioria das diretrizes definidas por Nielsen podem ser aplicadas no web design em geral, no entanto, o autor enfatiza que elas devem ser seguidas principalmente na construção da homepage. Em geral a homepage é a primeira e provavelmente a última oportunidade de atrair e manter cada cliente (Nielsen e Tahir, 2001).

É recomendado o uso dessas diretrizes como uma "checklist", observando a quais delas a homepage atual atende e a futura deverá atender. Os autores também comentam que não são doutrinas, elas podem ser “quebradas" se necessário, mas com prudência. É válido incluir a experiência dos usuários do projeto em questão.

\subsection{Os 113 itens de ação.}

Os 113 itens de ação propostos por Nielsen (2001) serviram para avaliar a homepage anterior, correspondendo às diretrizes de usabilidade.

O resultado final obtido na avaliação da homepage anterior do Telessaúde foi de $48 \%$. Segundo Nielsen (2001), o resultado tomado é muito fraco, até mesmo catastrófico. Por conseguinte, um novo projeto precisou ser estabelecido, pois o anterior definitivamente não atendia às diretrizes fundamentais de usabilidade.

Uma nova medida de atuação precisou ser tomada para que os usuários os quais tanto necessitam desse website não fossem mais prejudicados. Com isso, também houve oportunidade de atrair novos usuários e dar mais credibilidade às instituições envolvidas. Nielsen ainda aformoseia:

"Embora diversas análises dos sites se concentrem nos aspectos negativos do que existe de errado em cada design individual, as diretrizes oferecem uma perspectiva construtiva de como construir uma homepage com ótimo aproveitamento, desde o início." (NIELSEN E TAHIR, 2001)

Aplicou-se então, em seguida, a metodologia de Garrett (já apresentada neste trabalho) para a construção de uma nova interface para a homepage do Sistema Catarinense de Telessaúde e Telemedicina.

\subsection{Análise de similar}

Os Telessaúde tomados como principais referências em quesitos de design e divulgação são os da Universidade Estadual do Rio de Janeiro e da Universidade Federal do Rio Grande do Sul. Decidiu-se por analisar um website do Telessaúde UERJ $^{3}$ por ser, dentro dos Telessaúdes do país, um dos com melhor estética e usabilidade.

Para isso foi utilizada a lista de diretrizes simplificada baseada nas avaliações eurísticas de Nielsen elaborada por Pete Meyers em seu website "drpete.co"4. Essa lista foi selecionada por conseguir resumir as principais diretrizes de Nielsen de uma forma sucinta que possa ser aplicada em todas as páginas do website.

\section{Desenvolvimento}

\subsection{Elaboração das personas}

Com base nas pesquisas realizadas com usuários, elaborou-se uma persona para cada um dos três serviços que utilizam frequentemente a plataforma online do

${ }^{3}$ Disponível em: http://www.telessaude.uerj.br/ (Acessado em 25 de setembro de 2016).

${ }^{4}$ Disponível em: http://drpete.co/topic/25-point-websiteusability-checklist (Acessado em 25 de setembro de 2016). 


\section{$16^{\circ}$ \\ ERGODESIGN USIHC CINAHPA}

$16^{\circ}$ Ergodesign - Congresso Internacional de Ergonomia e Usabilidade de Interfaces Humano Tecnológica: Produto, Informações Ambientes Construídos e Transporte

$16^{\circ}$ USIHC - Congresso Internacional de Ergonomia e Usabilidade de Interfaces Humano Computador

CINAHPA | 2017 - Congresso Internacional de Ambientes Hipermídia para Aprendizagem.
Telessaúde e Telemedicina.

\subsection{Grupo de foco}

Os grupos de foco variaram de acordo com a disponibilidade dos membros de cada principal serviço do Telessaúde e da Telemedicina. Cada reunião durou de trinta minutos a uma hora e meia, os grupos menores (minigrupos de foco) em geral duraram menos. Todas as reuniões foram gravadas, com consentimento dos participantes.

Com as reuniões pôde-se reunir informações importantes sobre as dificuldades que os funcionários estão tendo com a plataforma atual, assim como quais são as recorrentes reivindicações vindas dos usuários externos. Seguiu-se então para a próxima etapa.

\subsection{Técnica de Cardsorting}

Para decidir quais seriam as tags utilizadas no cardsorting que nomeariam os itens de menu e sub menu fora feita uma reunião entre a pesquisadora e seus chefes responsáveis pelo projeto.

Para facilitar o acesso a distância, optou-se pela plataforma de cardsorting online ${ }^{5}$. Participaram do teste dez participantes, sendo eles de dentro ou fora da equipe de trabalho, representando o público alvo do website.

O método de avaliação dos dados obtidos foi o chamado “informal”. Segundo Santa Rosa (2012), o método de avaliação informal é uma inspeção visual simples dos dados de cardsorting que fornece ao pesquisador uma noção a respeito do modelo mental dos usuários. De tal maneira, é possível inferir como as pessoas intuitivamente entendem as relações entre os elementos. Pode-se, por fim, reconhecer padrões por meio de agrupamento e rotulagem semelhantes.

"No modo informal, o objetivo não é a busca de uma resposta definitiva, mas sim a procura de novas visões e ideias." (MAURER E WARFEL, 2004, APUD SANTAROSA 2012)

\subsection{Mapa de navegação}

Com base no resultado dos testes de cardsorting podese concluir a seguinte estrutura para arquitetura de navegação para o website:

\footnotetext{
${ }^{5}$ A qual pode ser encontrada no website: https://www.optimalworkshop.com
}

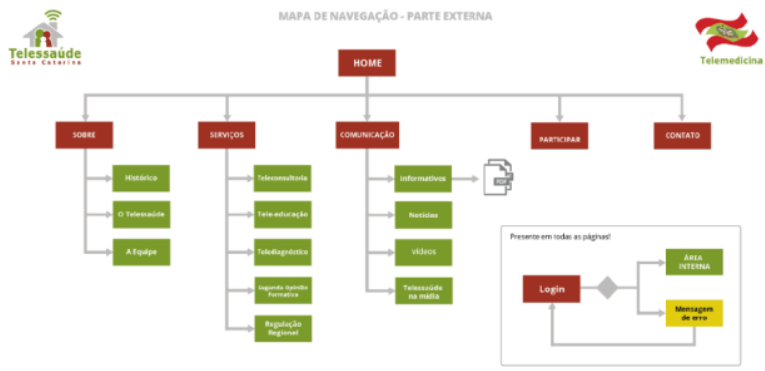

\subsection{Wireframe}

Após decidida a estrutura que o website como um todo tomaria, partiu-se para estruturação geral das páginas por meio dos wireframes. Depois de diversas reuniões, tomando as necessidades pontuais para elaboração da página inicial, pensou-se em uma estrutura compacta que pudesse acoplar todas as informações necessárias, atendendo maior parte possível das solicitações de cada serviço/diretoria dentro da organização.

Pela página inicial fez-se um grid base a ser seguido por todas as outras páginas. Utilizou-se também linhas guias indicando o tamanho ideal para a resolução da página em $100 \%$. O tamanho escolhido para largura do corpo da página foi $1000 \mathrm{px}$, enquanto a altura é flexível dependendo da quantidade de conteúdo a ser adicionada. Para o cabeçalho ficou definido $125 \mathrm{px}$ de altura e para o rodapé 1280 px de largura por 200px de altura.

\subsection{Finalização da interface}

Para a interface final buscou-se uma estética mais "clean", tendo como predomínio o branco e o cinza presentes na identidade da marca do Telessaúde. Também se optou por tendências ligadas ao flat design, esperando impressão mais moderna, de forma que o site não ficasse obsoleto em pouco tempo. Para os botões de serviços utilizou-se as cores definidas na identidade dos mesmos, com baixa opacidade.

Para a tipografia escolheu-se a fonte "Open Sans", a qual é também utilizada para os trabalhos gráficos do Telessaúde. Essa, por sua vez, é uma fonte "sans serif", concedendo-lhe a característica de fácil leitura nas telas de computadores e dispositivos móveis, mesmo em tamanhos reduzidos.

\subsubsection{Página Inicial}

A disposição dos elementos em geral foi modificada desde a elaboração do wireframe. Novos submenus
Realização:

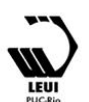




\section{$16^{\circ}$ \\ ERGODESIGN USIHC CINAHPA}

foram adicionados, assim como o serviço "RUTE" e a seção com link para a página do e-SUS. O tipo de menu escolhido foi o em cascata, que "se abre" cada vez que o usuário passa o mouse sobre ele. A página inicial conta com um slider para notícias e chamadas pontuais. Em seguida com botões que levam às páginas dos serviços, completando assim a "primeira tela".

$\mathrm{Na}$ segunda tela, a agenda possui um formato mais organizado que a presente no website obsoleto. Ao seu lado um pequeno box com chamadas para as notícias mais recentes, linkadas à página de "Notícias" da "Comunicação". Logo abaixo as principais publicações e os vídeos em destaque também ganham espaço.

O rodapé é amplo e dividido em duas partes, pois houve a necessidade de priorizar as instituições apoiadoras dos governos federal e estadual. $\mathrm{O}$ ícone de pesquisa teve de ser posto fora de um local de destaque em função do cabeçalho já estar sobrecarregado com duas boxes de acesso as quais precisam ficar presentes em todas as páginas.

Também há um adicional presente em todas as páginas: A pequena box flutuante do lado esquerdo superior da tela. Ela se adaptará à cada resolução e aparecerá mesmo quando a pessoa "rolar" a tela para baixo. Nela estão presentes os botões de aumento/diminuição de contraste, aumento/diminuição do tamanho da fonte e atalhos para as páginas de cada serviço.

Utilizou-se então a página inicial como base para criação de um template para as próximas páginas. Mantendo os padrões de fonte, disposição e cor, assim como cabeçalho, rodapé e o box móvel da lateral.

\section{Conclusão}

A conclusão obtida foi que o website dos sistemas de Telessaúde e Telemedicina necessita de atualização. Encontrou-se então uma oportunidade para melhoria desse sistema, facilitando a vida de seus usuários e profissionais, oferecendo o serviço de elaborar a interface da homepage para o futuro website.

Tendo como base os estudos efetuados nos livros de exímios autores especializados na área de web design, concluiu-se a construção da parte visual da homepage, assim como de todas as outras páginas, enfatizando aspectos de usabilidade, estética, cor, entre outros.

Como sugestão de continuidade ao projeto, serão realizados protótipos com as telas criadas (utilizado a ferramenta Marvel, por exemplo), assim como testes de usabilidade com os perfis de públicos selecionados. Podendo, desta forma, cooperar com a implementação do website da melhor forma possível.

Este projeto trouxe como principais ganhos a modernização da plataforma virtual para o Telessaúde Santa Catarina, tornando o acesso para os usuários e o trabalho dos colaboradores mais ergonômica e facilitada. Assim como também auxiliará na divulgação dos trabalhos efetuados pela equipe de comunicação, ampliando o conhecimento do público em geral sobre o Telessaúde.

\section{BIBLIOGRAFIA}

GARRETT, Jesse J. The elements of user experience. Berkeley: New Riders Press, 2003.

MULLING, Tobias Tessmann. Design experiencial, da teoria a práxis: recomendações para o projeto de hipermídias experienciais. Dissertação de mestrado, UFSC, 2010

NIELSEN, Jacob. TAHIR, Marie. Homepage Usability: 50 Websites Deconstructed. New Riders Press, 1a. edição, 2001.

NIELSEN, Jacob. Designing Web Usability: The Practice of Simplicity. New Riders Publishing, Indianapolis, 1999.

NIELSEN, Jacob. Usability Engineering. Academic Press, Boston, 1993.

SANTA ROSA, José Guilherme. MORAES, Anamaria de. Avaliação e projeto no design de interfaces. Editora 2AB, 1a. edição. Teresópolis, RJ, 2012.
Realização:

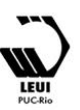

